\title{
Correlation of 2-Methoxyestradiol Levels in Cord Blood and Complications of Prematurity
}

\author{
CARMEN M. BARNES, THOMAS F. MCELRATH, JUDAH FOLKMAN, AND ANNE R. HANSEN
}

Department of Surgery [C.M.B., J.F.], Department of Medicine [A.B.H.], Children's Hospital Boston, Boston, Massachusetts 02115; Department of Obstetrics and Gynecology [T.F.M.], Brigham and Women's Hospital, Boston, Massachusetts 02115; Harvard Medical School [C.M.B., J.F., A.B.H., T.F.M.], Boston, Massachusetts 02115

\begin{abstract}
ME2) is a potent antiangiogenic molecule that inhibits the expression of hypoxia-inducible factor (HIF)- $1 \alpha$ and, consequently, of VEGF and other HIF- $1 \alpha$ target genes. Although $2 \mathrm{ME} 2$ is elevated during pregnancy in maternal serum, its presence in fetal fluids and its impact in neonatal health are unknown. In this study, we 1) described normal levels of 2ME2 in maternal blood, cord blood, breast milk, and amniotic fluid, and 2) compared a composite measure of perinatal outcome between infants born with high and low levels of $2 \mathrm{ME} 2$. We found that $2 \mathrm{ME} 2$ was significantly decreased in all fluids compared with prepartum maternal serum. After stratifying babies by $2 \mathrm{ME} 2$ exposure levels, we observed no differences in the vulnerability to impaired lung development or to complications involving aberrant angiogenesis or vascular leak, such as necrotizing enterocolitis (NEC), intraventricular hemorrhage (IVH), posthemorrhagic hydrocephalus (PHH), and retinopathy of prematurity (ROP). In summary, fetal 2ME2 concentrations do not appear to affect neonatal outcome. (Pediatr Res 67: 545-550, 2010)
\end{abstract}

$I^{\prime}$ has been known for more than two decades that 2-methoxyestrogens dramatically increase during pregnancy as a function of gestational age (GA) in maternal serum and cord blood (1). 2-methoxyestrogens include the 2-methoxyestradiol (2ME2) and the inactive metabolite 2-methoxyestrone (2ME1). The naturally occurring estradiol metabolite, 2ME2, has little to no estrogenic activity but has antiproliferative, antiangiogenic, and antitumor properties (2,3). 2ME2 suppresses the expression of hypoxia-inducible factors (HIF)- $1 \alpha$ and HIF- $2 \alpha$ both in vivo (4-6) and in vitro (4). More recently, it was demonstrated that 2ME2 levels were significantly reduced in pregnant women with severe preeclampsia compared with those without preeclampsia or those with gestational hypertension (7). The 2ME2 levels in fluids of the affected fetus and neonate, namely cord blood, amniotic fluid, and breast milk, are unknown.

Premature infants are at increased risk for developing complications associated with either deficient or excessive angiogenesis. We hypothesized that an imbalance in fetal 2ME2 could influence the outcomes of preterm infants, some of whose complications can be attributed to deficient angiogenesis and others to excess. Several groups have established that

Received July 30, 2009; accepted January 4, 2010.

Correspondence: Anne Hansen, M.D., Division of Newborn Medicine, Children's Hospital Boston, Boston MA 02115; e-mail: anne.hansen@ childrens.harvard.edu Supported by the Lee and Laura Munder Fund.

No conflict of interest pertains to this source of funding. inhibition of angiogenesis plays an important role in the pathogenesis of RDS and bronchopulmonary dysplasia (BPD). In babies with either severe RDS or BPD, VEGF is decreased in cord blood (8) and tracheal aspirates (9). In animal models of RDS and BPD, administration of angiogenesis inhibitors dramatically suppressed normal lung development $(10,11)$. HIF transcription factors were found to be significantly decreased in animal models or RDS (12), and their activation improved lung function $(13,14)$. Given that $2 \mathrm{ME} 2$ is an antiangiogenic inhibitor that can downregulate HIF- $1 \alpha$ and HIF-2 $\alpha$ (4), we hypothesized that there would be a direct relationship between 2ME2 cord blood level at birth and risk of RDS and/or BPD in the preterm neonate.

Conversely, we hypothesized that infants born with high 2ME2 would have a reduced incidence of complications of prematurity associated with either perinatal or postnatal hypoxia, increased blood vessel growth, and/or vascular leak. During hypoxia, HIF1 $\alpha$ accumulates and activates the expression of proteins that promote angiogenesis and vascular leak, such as VEGF and angiopoietin-2, and of inflammatory cytokines (15). 2ME2 counteracts the angiogenic and inflammatory effects of HIF1 $\alpha(4,5,16)$. Hypoxia is an important risk factor in the pathogenesis of necrotizing enterocolitis (NEC) (17), and intraventricular hemorrhage (IVH) (18). High oxygen concentrations followed by hypoxia contribute to the development of retinopathy of prematurity (ROP) $(19,20)$. Excessive vascular leak is observed in NEC and IVH, and abnormal blood vessel formation is observed in ROP. Increased concentrations of VEGF are found in IVH (21), in cerebrospinal fluid of premature infants with posthemorrhagic hydrocephalus (PHH) (22), and in ROP (23). Increased angiopoietin-2 is observed in IVH (21). Genetic polymorphisms of VEGF (24) and inflammatory cytokines are implicated in NEC $(25,26)$. Two markers of hypoxia, activin A and hypoxanthine, are significantly increased in premature infants who develop IVH (27). Furthermore, antenatal administration of other angiogenesis inhibitors decreases the severity and incidence of germinal matrix hemorrhage in prematurely deliv-

Abbreviations: 2ME1, 2-methoxyestrone; 2ME2, 2-methoxyestradiol; GA, gestational age; BPD, bronchopulmonary dysplasia; E1, estrone; E2, estradiol; HIF-1 $\boldsymbol{\alpha}$, hypoxia-inducible factor 1 alpha; IVH, intraventricular hemorrhage; NEC, necrotizing enterocolitis; PHH, posthemorrhagic hydrocephalus; ROP, retinopathy of prematurity 
ered rabbits (21). On the basis of these observations, we hypothesized that high $2 \mathrm{ME} 2$ cord blood levels could translate into a decreased risk for NEC, IVH, PHH, and ROP.

\section{METHODS}

Subjects. This research was approved by the Investigational Review Board of Brigham and Women's Hospital, and sample collection occurred between September 2006 and March 2008. The study had two arms. In the first arm, we collected a total of 45 samples from five mothers and their term infants. All infants were delivered by elective cesarean section without labor. Sample collection included maternal blood (four samples from the same mother: intraoperatively and postpartum days 1,2 , and 3), intraoperative amniotic fluid at the time of hysterotomy, cord blood obtained before delivery of the placenta, and breast milk (postpartum days 2 and 3). The second arm consisted of a prospective cohort study of 152 cord blood samples and 20 amniotic fluid samples from consecutive preterm and term deliveries.

Clinical outcomes. The incidence of complications of prematurity decreases with GA, falling sharply from the borderline of viability in the 23rd to 25 th week of gestation until term. Completion of 32-wk gestation is considered to be a cutoff for the period at highest risk of major complications. Therefore, we asked whether cord blood 2ME2 correlated with neonatal outcome in premature infants born at $<33$ wk of gestation.

Our primary outcome was RDS, caused by developmental insufficiency of surfactant production. Secondary outcomes included BPD, NEC, IVH including PHH, and ROP. BPD, a chronic lung condition characterized by impaired alveolization and deficient vascular development, was defined as the need for supplemental oxygen at $36 \mathrm{wk}$ postmenstrual age. Relevant clinical information regarding RDS, BPD, NEC, IVH, PHH, and ROP was collected prospectively for all 107 infants $<33$ wk of gestation by real-time extraction from the medical record, augmented by questions to the medical team. There is a lack of published data on the potential effect of $2 \mathrm{ME} 2$ on RDS. Thus, we began by estimating a large reduction in incidence of RDS, with the expectation of refining estimates of the magnitude of the effect based on the signal perceived in our own data for future studies. Our study had $80 \%$ power to detect a $50 \%$ reduction in the risk of RDS $<32$ wk gestation at the 0.05 significance level. Given the level of RDS reduction we observed, we would have required a total of 3210 patients to obtain the same power at the same significance level.

Fluid collection and analysis of $2 M E 2$ and $2 M E 1$. All serum samples were collected in citrate tubes within 5 min of delivery. Plasma samples were obtained immediately after serum collection. Amniotic fluid was collected at the time of hysterotomy by surgically exposing the fetal membranes, piercing them with a flexible blunt plastic catheter, and aspirating $10 \mathrm{~mL}$ of amniotic fluid before amniorrhexis and delivery of the baby. All of the fluids were immediately stored at $-70^{\circ} \mathrm{C}$ until analyzed. None of the amniotic fluid samples contained blood or meconium.

Analysis of 2ME1 and 2ME2. The levels of both methoxyestrogens, 2ME1 and 2ME2, were determined by gas chromatography-mass spectrometry (GC-MS) at AAI Pharma (Neu Ulm Germany).

Samples were spiked with internal standard working solution, acidified, and extracted from plasma into toluene, followed by several cleanup steps. After extraction, samples were evaporated, derivatized, and analyzed by GC-MS in chemical ionization mode. The calibrated range for $2 \mathrm{ME} 2$ and
$2 \mathrm{ME} 1$ was $5-500 \mathrm{pg} / \mathrm{mL}$, with a defined lower limit of detection of 5.00 $\mathrm{pg} / \mathrm{mL}$, an overall accuracy of $1.35 \%$ bias, and overall precision of coefficient of variance $=10.06 \%$. Samples with concentrations higher than upper limit of calibrated working range were reanalyzed after appropriate dilution. For the analyzed samples, the low sensitivity range varied between $<6.25 \mathrm{pg} / \mathrm{mL}$ and $<50 \mathrm{pg} / \mathrm{mL}$. This variation reflects differences in initial sample volume and additional requirements for sample dilution (as in the case of breast milk samples because of high fat content).

Data analysis. 2ME2 and 2ME1 data are reported with medians and interquartile range. Because 29 (18.4\%) of the cord blood values were below the detection limit and we could, therefore, not be sure of the true underlying analyte distribution, we used nonparametric statistics for all comparisons (Wilcoxon Rank Sum and quantile regression). The $\chi^{2}$ tests were used to compute the correlation between 2ME2 levels and complications of prematurity. Computation of the ratio of 2ME2 to total 2-methoxyestrogen, defined as $2 \mathrm{ME} 2 / 2 \mathrm{ME}_{\mathrm{t}}$, where $2 \mathrm{ME}_{\mathrm{t}}=2 \mathrm{ME} 2+2 \mathrm{ME} 1$, was performed only for samples with values above the detection limits for both 2ME2 and 2ME1.

\section{RESULTS}

Normal distribution of $2 M E 2$ in maternal blood, cord blood, breast milk, and amniotic fluid. The relative distribution of total 2ME2 and 2ME1 was measured in the bodily fluids of five term mothers and their infants. The $2 \mathrm{ME} 2 / 2 \mathrm{ME}_{\mathrm{t}}$ ratio in all bodily fluids was used to evaluate differences in 2ME2 activation.

Antepartum maternal peripheral blood, collected preoperatively, had the highest 2ME2 and 2ME1 levels of all of the source fluids analyzed [median $2 \mathrm{ME} 2=2.29 \mathrm{ng} / \mathrm{mL}$ (interquartile range: $1.66-5.23 \mathrm{ng} / \mathrm{mL}$ ), median $=2 \mathrm{ME} 11.50$ $\mathrm{ng} / \mathrm{mL}$ (interquartile range: $0.81-3.49 \mathrm{ng} / \mathrm{mL}$ )]. Interestingly, $2 \mathrm{ME} 2$ constituted $\sim$ two thirds of the $2 \mathrm{ME} 2$ ratio in antepartum maternal peripheral serum $\left(2 \mathrm{ME} 2 / 2 \mathrm{ME}_{\mathrm{t}}=0.62 \pm 0.07\right)$. This is in contrast to the cord blood, amniotic fluid, and breast milk, where 2ME1 was the most abundant metabolite (Table 1). Within one day of delivery, 2ME2, but not 2ME1, sharply decreased to $1 \%$ of its antenatal value, yielding a half-life of $\sim 4 \mathrm{~h}$. Nearly $75 \%$ of all prepartum maternal $2 \mathrm{ME} 1$ remained at $24 \mathrm{~h}$ and slowly decreased over time, becoming the predominant 2-methoxyestrogen (Fig. 1).

Breast milk samples did not contain significant amounts of either 2-methoxyestrogen. 2ME2 was below detection level in all breast milk samples. 2ME1 was detectable above threshold levels in only one of five samples, and this corresponded to the mother with highest prepartum 2ME2 and 2ME1 levels

Table 1. 2ME2 and 2ME1 levels in paired maternal and fetal fuids (pilot study)

\begin{tabular}{|c|c|c|c|c|c|}
\hline \multirow[b]{2}{*}{$N=5$} & \multicolumn{2}{|c|}{ 2ME2 (pg/mL) } & \multicolumn{2}{|c|}{ 2ME1 (pg/mL) } & \multirow[b]{2}{*}{$\% 2 \mathrm{ME} 2 / 2 \mathrm{ME}^{*}$} \\
\hline & Mean $\pm \mathrm{SD}$ & Median (IQR) & Mean $\pm \mathrm{SD}$ & Median (IQR) & \\
\hline \multicolumn{6}{|l|}{ Maternal serum } \\
\hline Antepartum & $3514 \pm 2801$ & $2290(1840$ to 4280$)$ & $2390 \pm 2359$ & $1500(858$ to 2510$)$ & $62 \pm 7$ \\
\hline Postpartum d 1 & $55 \pm 53$ & $25(23$ to 116$)$ & $2616 \pm 2086$ & 1730 (1120 to 5000$)$ & $19 \pm 4$ \\
\hline Postpartum d $2 \dagger$ & $<20$ & $<10(<5$ to $<10)$ & $643 \pm 916$ & $256(207$ to 455$)$ & $<0.03$ \\
\hline Postpartum d $3 \dagger$ & $<10$ & $<5(<5$ to $<10)$ & $354 \pm 552$ & $116(113$ to 148$)$ & $<0.03$ \\
\hline \multicolumn{6}{|l|}{ Breast milk } \\
\hline Postpartum d $2 \dagger$ & $<50$ & $<50(<50$ to $<50)$ & $<97$ & $<50(12$ to 151$)$ & $<\mathrm{DL}$ \\
\hline Postpartum d $3 \dagger$ & $<50$ & $<50(<50$ to $<50)$ & $<85$ & $<50(<50$ to $<50)$ & $<\overline{D L}$ \\
\hline Cord blood $\ddagger$ & $<176$ & $<25(<10$ to 87$)$ & 462 & 212 (173 to 386$)$ & $32 \pm 4$ \\
\hline Amniotic fluid & $<18$ & $5.5(<5$ to 31$)$ & 56 & 16.7 (13.3 to 39.2$)$ & $29 \pm 14$ \\
\hline
\end{tabular}

* 2ME2/2ME $=2 \mathrm{ME} 2 /(2 \mathrm{ME} 2+2 \mathrm{ME} 1)$; ratios could only be determined for samples in which both $2 \mathrm{ME} 2$ and $2 \mathrm{ME} 1$ levels were above detection limit.

$\dagger$ On days 2 and 3, 2ME2 was below detection limit in 4/5 maternal serum and 5/5 breast milk samples; $2 \mathrm{ME} 1$ was below threshold in 4/5 breast milk samples. $\$ 2$ ME2 levels were below detection limit for three of five cord blood and two of five amniotic fluid samples.

$\mathrm{IQR}$, interquartile range; $<\mathrm{DL}$, less than detection limit. 
( $>8060$ and $>6410 \mathrm{pg} / \mathrm{mL}$, respectively). For this sample, the $2 \mathrm{ME} 1$ concentration in breast milk was $\sim 12 \%$ of that found in maternal serum at the same time points (Table 1).

From the two fetal fluids measured, cord blood contained higher 2-methoxyestrogen levels than amniotic fluid, and 2ME1 was the predominant metabolite in both. Large variability was observed within this five mother/fetus set for both 2ME2 and 2ME1 levels, with three of five cord blood and two of five amniotic fluid samples having levels below detection. Median cord blood 2ME1 and 2ME2 values were 20 versus $2.6 \%$ compared with their paired prepartum maternal serum 2ME1 and 2ME2 counterparts, respectively. Median amniotic fluid 2ME1 and 2ME2 levels were even lower, representing only 1.6 and $0.5 \%$ of prepartum maternal serum $2 \mathrm{ME} 1$ and 2ME2 levels, respectively. In combination with the additional 23 amniotic fluid samples collected between 16 and $40 \mathrm{wk}$ of gestation, we found that amniotic fluid 2ME2 levels were not correlated with either GA or birth weight. Only eight of $28 \mathrm{had}$ 2ME2 and 2ME1 levels above the detection limit $(25 \mathrm{pg} / \mathrm{mL})$, and in these samples, the $2 \mathrm{ME}^{2} / 2 \mathrm{ME}_{\mathrm{t}}$ ratio was $0.29 \pm 0.10$.

Increase of fetal $2 \mathrm{ME} 2$ at term. To address changes in fetal levels during pregnancy, we measured 2ME2 and 2ME1 in 157 cord blood samples spanning a wide range of GAs. The patient characteristics are tabulated in Table 2. We observed that cord blood 2ME2 and 2ME1 levels were correlated with GA, increasing exponentially at term (Fig. 2). When samples were grouped according to GA into premature infants born

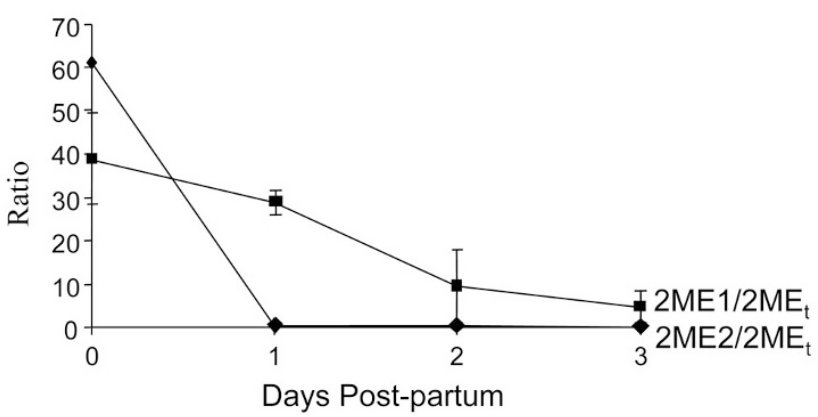

Figure 1. Change in $2 \mathrm{ME} 1$ and $2 \mathrm{ME} 2$ levels relative to antepartum $2 \mathrm{ME}_{\mathrm{t}}$ levels. Each data point represents the relative mean ratio of $2 \mathrm{ME} 2 / 2 \mathrm{ME}_{\mathrm{t}}$ and $2 \mathrm{ME} 1 / 2 \mathrm{ME}_{\mathrm{t}}$ for five mothers, except for day 1 postpartum, which of is the average of three of five mothers. between 24 and 32 completed wk gestation, premature infants born between 33 and 36 wk gestation, and term infants born between 37 and 42 wk gestation, only the term group was statistically different for either 2ME2 or 2ME1 (Fig. 2). Median cord 2ME2 and 2ME1 (interquartile range) varied in these three groups (Table 2). The average $2 \mathrm{ME} 2 / 2 \mathrm{ME}_{\mathrm{t}}$ ratio in cord blood was $0.32 \pm 0.11$, similar to that found in amniotic fluid, and this ratio was unchanged across all GA groups (Table 2).

We investigated the association of 2ME2 and birth weight given the well-known dependence of birthweight and GA in infant outcomes. Significant differences were observed for 2ME1 but not 2ME2 levels when comparing extremely low birth weight infants $(<1500 \mathrm{~g})$ and those weighing $\geq 1500 \mathrm{~g}$ of all GAs $\left(p_{2 \mathrm{ME} 1}=0.031, p_{2 \mathrm{ME} 2}=0.378\right)$. When all infants were grouped by $1 \mathrm{~kg}$ birth weight increments $(<1000,1000-$ 2000, 2000-3000, and 3000-4000 g), 2ME1, but not 2ME2 levels $(p=0.207)$, were found to be significantly correlated to birthweight: mean 2ME1 by birth weight increment: 123 (97-262), 167 (65-304), 204 (217-498), 359 (213-1013), respectively; $(p=0.001)$. Only when 2ME2 levels were

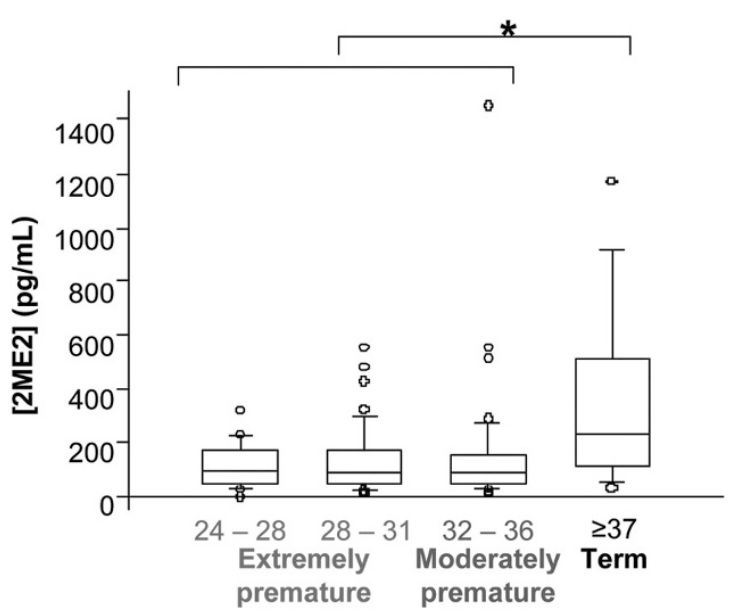

Figure 2. Correlation of cord $2 \mathrm{ME} 2$ concentration with GA. Data displayed as median with 25 th and 75 th percentile. $n=157$ samples, divided as follows: 31 from preterm infants $<28$ wk of gestation, 76 from preterm infants $28-32$ completed wk of gestation, 20 from preterm infants 33-36 completed wk of gestation, and 15 from term infants $37-42$ wk of gestation.

Table 2. Characteristics of cord blood samples

\begin{tabular}{|c|c|c|c|c|}
\hline$N$ & $\begin{array}{c}\text { Extremely premature } \\
\qquad(N=107)\end{array}$ & $\begin{array}{l}\text { Moderately premature } \\
\qquad(N=31)\end{array}$ & $\begin{array}{c}\text { Term } \\
(N=19)\end{array}$ & $p$ \\
\hline GA range (wk) & $24-32$ & $33-36$ & $37-41$ & \\
\hline GA (wk) & $29.9(27.4-31.7)$ & $33.7(33.1-34.3)$ & $39.3(38.5-40)$ & $<0.001$ \\
\hline Birth weight & $1370(922-1647)$ & $1960(1705-2307)$ & $3232(3011-3382)$ & $<0.001$ \\
\hline Twins or triplets (\%) & $72(67)$ & $19(61)$ & $0(0)$ & $<0.001$ \\
\hline Gender, male $(\%)$ & $67(63)$ & $19(61)$ & $8(42)$ & 0.241 \\
\hline 2ME2 (pg/mL) & $62(38-149)$ & $72(43-148)$ & $203(97-509)$ & 0.028 \\
\hline $2 \mathrm{ME} 1(\mathrm{pg} / \mathrm{mL})$ & $160(81-308)$ & $192(83-301)$ & $386(213-1380)$ & $<0.001$ \\
\hline 2ME2/2ME & $0.31(0.23-0.41)$ & $0.32(0.23-0.42)$ & $0.26(0.17-0.34)$ & 0.083 \\
\hline \multicolumn{5}{|l|}{ Maternal characteristics } \\
\hline Age & $33(27.2-36)$ & $33(30-38)$ & $33(29.5-34)$ & 0.317 \\
\hline Gravity & $2(1-3)$ & $3(1-4)$ & $2(2-3)$ & 0.129 \\
\hline Parity $=0(\%)$ & $69(64)$ & $16(52)$ & $5(26)$ & 0.006 \\
\hline
\end{tabular}

Values are given as mean (range) or $n(\%)$. 
compared in infants weighing $<2500 \mathrm{~g}$ with those weighing $\geq 2500$ g did 2ME2 become significant.

Composite measure of perinatal outcome between extremely premature infants born with high and low levels of 2ME2. The histogram representing the distribution of 2ME2 levels in premature infants born between 24 and 32 completed wk of gestation follows an exponential decay with one half of all infants having 2ME2 levels of $50 \mathrm{pg} / \mathrm{mL}$ or lower (data not shown). We, therefore, asked whether infants born with high 2ME2 levels, defined as those in the top 25\% (2ME2 $\geq 151$ $\mathrm{pg} / \mathrm{mL} ; n=26$ ), had differences in neonatal outcome compared with infants born in the bottom $75 \%$ of $2 \mathrm{ME} 2$ (2ME2 $<151 \mathrm{pg} / \mathrm{mL}, n=81$ ). We found that high cord blood 2ME2 did not correlate with an increased incidence of RDS or BPD, nor did it correlate with a decreased incidence of NEC, IVH, or ROP (Table 3, left). We also considered that low levels of 2ME2 might be deleterious and examined outcomes for infants in the bottom $25 \%$ (2ME2 $\leq 40 \mathrm{pg} / \mathrm{mL} ; n=29$ ) compared with top $75 \%(2 \mathrm{ME} 2>40 \mathrm{pg} / \mathrm{mL}, n=78)$. Infants with low 2ME2 had similar rates of pulmonary complications (RDS and BPD) and were equally susceptible to other complications of prematurity (NEC, IVH, and ROP, Table 3, right).

\section{DISCUSSION}

To our knowledge, ours is the first study to independently measure the levels of total 2ME2 and 2ME1 in maternal serum, amniotic fluid, breast milk, and cord blood at term, and cord blood across a wide range of GAs and to determine the relative proportion of $2 \mathrm{ME} 2$ in 2-methoxyestrogen levels. The RIA previously used by others could not distinguish between 2ME1 and 2ME2 (1). However, the active metabolite 2ME2 was recently measured by HPLC and was found to be elevated in maternal serum at mid-gestation (21-29 wk of gestation) (7). We found that total 2ME2 is present at high concentra- tions in maternal serum at term (median $=2.3 \mathrm{ng} / \mathrm{mL}$ ), and at lower but still significantly elevated levels in cord blood $($ median $=203 \mathrm{pg} / \mathrm{mL})$.

Steroid proteins can exist bound to proteins in serum or in a free (biologically active) state. The method used here, GC-MS, measures the total concentration of 2ME2 and 2ME1 (free and protein bound forms) and cannot distinguish between the two forms. Although it is not known whether endogenous 2ME2 is bound to serum proteins during pregnancy, 2ME2 was not found to be significantly or specifically bound to plasma proteins in the serum of clinical cancer patients treated with this agent $(28,29)$. Therefore, we expect most 2ME2 measured here to be in the free state.

Although, in maternal serum, 2ME2 is the main 2-methoxyestrogen $(62 \pm 7 \%, n=5)$, it is the least abundant metabolite in cord blood, accounting for only $\sim 30 \%$ of the total 2-methoxyestrogen ratio. The $2 \mathrm{ME} 2 / 2 \mathrm{ME}_{\mathrm{t}}$ ratios in maternal and fetal serum can be explained by the distribution of $17-\beta$-hydroxysteroid dehydrogenase types 1 and 2 (17HSD $\beta 1$ and $17 \mathrm{HSD} \beta 2)$ in the placenta. $17 \mathrm{HSD} \beta 1$, located in the syncytiotrophoblast and in direct contact with the maternal side of the uterine-placental unit (30-32), converts $17 \beta$ estrone (E1) into $17 \beta$-estradiol (E2) and $2 \mathrm{ME} 1$ into $2 \mathrm{ME} 2$. Conversely, $17 \mathrm{HSD} \beta 2$ is expressed in fetal placental vessels and is in contact with fetal blood $(31,33)$. This enzyme inactivates E2 and 2ME2 to E1 and 2ME1, respectively. It has been proposed that this enzyme protects the fetus from estradiol and androgens, and we propose that it may also protect the fetus from 2ME2. Importantly, the E2/(E2 + E1) ratio in maternal and fetal serum is similar to that for $2 \mathrm{ME} 2 / 2 \mathrm{ME}_{\mathrm{t}}$. E2 is more abundant in maternal serum $(72 \%)$, whereas E1 is more abundant in fetal serum [76\%; data from (34)].

In terms of metabolite concentration, 2-methoxyestrogens are underrepresented in the fetal circulation compared with their E2 and E1 counterparts. The total concentration of

Table 3. Correlation between $2 M E 2$ level and complications of prematurity

\begin{tabular}{|c|c|c|c|c|c|c|}
\hline Incidence & Lower $75 \% *$ & Top $25 \% *$ & $p$ & Lower $25 \% *$ & Top $75 \% *$ & $p$ \\
\hline Median 2ME2 (pg/mL) & 49 & 225 & & 23 & 105 & \\
\hline Range $(\mathrm{pg} / \mathrm{mL})$ & $<10-150$ & $151-1450$ & & $<10-38.5$ & $40-1450$ & \\
\hline $\mathrm{N}$ & 81 & 26 & & 29 & 78 & \\
\hline RDS & $45(55.6)$ & $12(46)$ & 0.403 & $17(59)$ & $40(51.3)$ & 0.499 \\
\hline $\mathrm{BPD}$ & $20(24.7)$ & $6(23)$ & 0.867 & $6(20.7)$ & $20(25.6)$ & 0.596 \\
\hline Possible NEC & $1(1.2)$ & $0(0)$ & 0.569 & $0(0)$ & $1(1.3)$ & 0.540 \\
\hline Medical NEC & $1(1.2)$ & $1(3.8)$ & 0.392 & $1(3.4)$ & $1(1.3)$ & 0.462 \\
\hline Surgical NEC & $4(4.9)$ & $1(3.8)$ & 0.818 & $2(6.9)$ & $3(3.8)$ & 0.506 \\
\hline Intracranial hemorrhage: total & $13(16)$ & $6(23)$ & 0.415 & $3(10.3)$ & $16(20.5)$ & 0.221 \\
\hline Germinal matrix hemorrhage & $5(6.1)$ & $4(15.3)$ & 0.141 & $1(3.4)$ & $8(10.3)$ & 0.259 \\
\hline IVH without ventricular dilation & $3(3.7)$ & $2(7.7)$ & 0.402 & $0(0)$ & $5(6.4)$ & 0.163 \\
\hline IVH with ventricular dilation & $3(3.7)$ & $0(0)$ & 0.320 & $2(6.9)$ & $1(1.3)$ & 0.118 \\
\hline Posthemorrhagic hydrocephalus & $4(4.9)$ & $0(0)$ & 0.248 & $2(6.9)$ & $2(2.6)$ & 0.294 \\
\hline Parenchymal hemorrhage & $4(4.9)$ & $0(0)$ & 0.248 & $1(3.4)$ & $3(3.8)$ & 0.923 \\
\hline \multicolumn{7}{|l|}{ Periventricular leukomalacia } \\
\hline Echodensity & $2(2.5)$ & $1(3.8)$ & 0.711 & $0(0)$ & $3(3.8)$ & 0.284 \\
\hline Echolucency & $0(0)$ & $1(3.8)$ & 0.076 & $0(0)$ & $1(1.3)$ & 0.540 \\
\hline Total ROP & $20(24.7)$ & $6(23)$ & 0.867 & $6(20.7)$ & $20(25.6)$ & 0.596 \\
\hline ROP (stage 1) & $5(6.2)$ & $4(15.4)$ & 0.141 & $0(0)$ & $9(11.5)$ & 0.056 \\
\hline ROP (stage 2) & $12(14.8)$ & $1(4.2)$ & 0.136 & $4(13.8)$ & $9(11.5)$ & 0.751 \\
\hline ROP (stage 3) & $3(3.7)$ & $1(4.2)$ & 0.973 & $2(6.9)$ & $2(2.6)$ & 0.294 \\
\hline
\end{tabular}

* No. infants $(\%)$. 
maternal E1 + E2 ( 32 ng/mL; 34) is $80 \%$ of that found in fetal serum $(\sim 40 \mathrm{ng} / \mathrm{mL})$. In sharp contrast, the maternal 2-methoxyestrogen concentration $(2 \mathrm{ME} 2+2 \mathrm{ME} 1=5.9$ $\mathrm{ng} / \mathrm{mL})$ is 10 times greater than that found for fetal 2-methoxyestrogen $(0.59 \mathrm{mg} / \mathrm{mL})$, suggesting a restriction of both 2ME1 and 2ME2 from the fetal circulation compared with their estrogen counterparts. In maternal serum, the combined 2ME2 and 2ME1 levels are $\sim 20 \%$ of the maternal estrogen $(\mathrm{E} 2+\mathrm{E} 1)$ levels, whereas in cord blood, they only correspond to $1.5 \%$.

The sharp disparity in maternal and fetal 2ME2 levels is similar to that found for the antiangiogenic soluble VEGF receptor 1 (s-VEGFR1), also known as sFlt-1 (35) (36). Both s-VEGFR1 and 2ME2 are found at nanograms per milliliter levels in maternal serum and picograms per milliliter levels in fetal serum. Other angiogenic inhibitors are also present at either greater concentrations in maternal serum than cord blood [for example, soluble endoglin (s-Eng) (37)] or at comparable amounts [VEGF receptor 2 (VEGFR2) (35) and endostatin (38)]. Conversely, VEGF is present at lower concentrations in maternal serum $(35,36,39)$. The placenta seems to orchestrate a preferential release of 2ME2, s-VEGFR1, and other angiogenesis inhibitors into maternal blood, making the maternal environment relatively antiangiogenic, whereas keeping the fetal environment relatively proangiogenic.

In humans, the maximum attainable 2ME2 serum levels in phase I clinical cancer patients was found to be $3-13 \mathrm{ng} / \mathrm{mL}$, comparable with the $2 \mathrm{ME} 2$ range found here for pregnant mothers. In cord blood, however, the 2ME2 level is almost two orders of magnitude lower. The lack of correlation of 2ME2 to complications of prematurity may be because of ineffective 2ME2 levels, even among the premature infants born with the highest 2 ME2 levels $(0.200-1.35 \mathrm{ng} / \mathrm{mL})$. For in vitro studies, induction of apoptosis and inhibition of HIF- $1 \alpha$ occur at micromolar 2ME2 concentrations (>300 ng/mL) $(4,5,40)$ and inhibition of MAP kinase activity and of DNA synthesis was observed at $100 \mathrm{nM}(30 \mathrm{ng} / \mathrm{mL} ; 41,42)$.

Preterm babies are unlikely to make significant quantities of their own 2ME2, and we found that breast milk is not a source of 2ME2. Therefore, 2ME2 exposure of preterm infants should be limited to that provided in utero by placental sources, and their levels will likely drop off rapidly after birth based on the $\sim 4$-h half-life of $2 \mathrm{ME} 2$ in maternal serum.

In conclusion, we found that despite the high 2ME2 concentrations in maternal serum at term gestation, $2 \mathrm{ME} 2$ is significantly shielded from the fetus. The fetal concentrations of $2 \mathrm{ME} 2$ that we observed do not appear to have either a positive or negative impact on RDS or other neonatal outcomes in extremely premature infants. Given the small sample size of our cohort study, validation of these results in a larger cohort study is warranted.

Acknowledgments. We thank Deirdre Greene, R.N. (Brigham and Women's Hospital) for her invaluable help with sample collection and processing, and data collection. This work is dedicated in loving memory of Dr. Judah Folkman.

\section{REFERENCES}

1. Berg D, Sonsalla R, Kuss E 1983 Concentrations of 2-methoxyoestrogens in human serum measured by a heterologous immunoassay with an 125I-labelled ligand. Acta Endocrinol (Copenh) 103:282-288

2. D'Amato RJ, Lin CM, Flynn E, Folkman J, Hamel E 1994 2-Methoxyestradiol, an endogenous mammalian metabolite, inhibits tubulin polymerization by interacting at the colchicine site. Proc Natl Acad Sci USA 91:3964-3968

3. Mooberry SL 2003 New insights into 2-methoxyestradiol, a promising antiangiogenic and antitumor agent. Curr Opin Oncol 15:425-430

4. Mabjeesh NJ, Escuin D, LaVallee TM, Pribluda VS, Swartz GM, Johnson MS, Willard MT, Zhong H, Simons JW, Giannakakou P 2003 2ME2 inhibits tumor growth and angiogenesis by disrupting microtubules and dysregulating HIF. Cancer Cell 3:363-375

5. Ricker JL, Chen Z, Yang XP, Pribluda VS, Swartz GM, Van Waes C 2004 2-methoxyestradiol inhibits hypoxia-inducible factor 1alpha, tumor growth, and angiogenesis and augments paclitaxel efficacy in head and neck squamous cell carcinoma. Clin Cancer Res 10:8665-8673

6. Becker CM, Rohwer N, Funakoshi T, Cramer T, Bernhardt W, Birsner A, Folkman J, D'Amato RJ 2008 2-methoxyestradiol inhibits hypoxia-inducible factor- $1 \alpha$ and suppresses growth of lesions in a mouse model of endometriosis. Am J Pathol 172:534-544

7. Kanasaki K, Palmsten K, Sugimoto H, Ahmad S, Hamano Y, Xie L, Parry S, Augustin HG, Gattone VH, Folkman J, Strauss JF, Kalluri R 2008 Deficiency in catechol-O-methyltransferase and 2-methoxyoestradiol is associated with preeclampsia. Nature 453:1117-1121

8. Tsao PN, Wei SC, Chou HC, Su YN, Chen CY, Hsieh FJ, Hsieh WS 2005 Vascular endothelial growth factor in preterm infants with respiratory distress syndrome. Pediatr Pulmonol 39:461-465

9. Lassus P, Turanlahti M, Heikkila P, Andersson LC, Nupponen I, Sarnesto A, Andersson S 2001 Pulmonary vascular endothelial growth factor and Flt-1 in fetuses, in acute and chronic lung disease, and in persistent pulmonary hypertension of the newborn. Am J Respir Crit Care Med 164:1981-1987

10. Jakkula M, Le Cras TD, Gebb S, Hirth KP, Tuder RM, Voelkel NF, Abman SH 2000 Inhibition of angiogenesis decreases alveolarization in the developing rat lung. Am J Physiol Lung Cell Mol Physiol 279:L600-L607

11. Le Cras TD, Markham NE, Tuder RM, Voelkel NF, Abman SH 2002 Treatment of newborn rats with a VEGF receptor inhibitor causes pulmonary hypertension and abnormal lung structure. Am J Physiol Lung Cell Mol Physiol 283:L555-L562

12. Grover TR, Asikainen TM, Kinsella JP, Abman SH, White CW 2007 Hypoxiainducible factors HIF-1alpha and HIF-2alpha are decreased in an experimental model of severe respiratory distress syndrome in preterm lambs. Am J Physiol Lung Cell Mol Physiol 292:L1345-L1351

13. Asikainen TM, Chang LY, Coalson JJ, Schneider BK, Waleh NS, Ikegami M, Shannon JM, Winter VT, Grubb P, Clyman RI, Yoder BA, Crapo JD, White CW 2006 Improved lung growth and function through hypoxia-inducible factor in primate chronic lung disease of prematurity. FASEB J 20:1698-1700

14. Asikainen TM, Waleh NS, Schneider BK, Clyman RI, White CW 2006 Enhancement of angiogenic effectors through hypoxia-inducible factor in preterm primate lung in vivo. Am J Physiol Lung Cell Mol Physiol 291:L588-L595

15. Jiang BH, Semenza GL, Bauer C, Marti HH 1996 Hypoxia-inducible factor 1 levels vary exponentially over a physiologically relevant range of $\mathrm{O}_{2}$ tension. Am J Physiol 271:C1172-C1180

16. Hagen T, D'Amico G, Quintero M, Palacios-Callender M, Hollis V, Lam F, Moncada S 2004 Inhibition of mitochondrial respiration by the anticancer agent 2-methoxyestradiol. Biochem Biophys Res Commun 322:923-929

17. Baregamian N, Rychahou PG, Hawkins HK, Evers BM, Chung DH 2007 Phosphatidylinositol 3-kinase pathway regulates hypoxia-inducible factor-1 to protect from intestinal injury during necrotizing enterocolitis. Surgery 142:295-302

18. Kadri H, Mawla AA, Kazah J 2006 The incidence, timing, and predisposing factors of germinal matrix and intraventricular hemorrhage (GMH/IVH) in preterm neonates. Childs Nerv Syst 22:1086-1090

19. Smith LE, Wesolowski E, McLellan A, Kostyk SK, D'Amato R, Sullivan R, D'Amore PA 1994 Oxygen-induced retinopathy in the mouse. Invest Ophthalmol Vis Sci 35:101-111

20. Miyamoto N, Mandai M, Takagi H, Suzuma I, Suzuma K, Koyama S, Otani A, Oh $\mathrm{H}$, Honda Y 2002 Contrasting effect of estrogen on VEGF induction under different oxygen status and its role in murine ROP. Invest Ophthalmol Vis Sci 43:2007-2014

21. Ballabh P, Xu H, Hu F, Braun A, Smith K, Rivera A, Lou N, Ungvari Z, Goldman SA, Csiszar A, Nedergaard M 2007 Angiogenic inhibition reduces germinal matrix hemorrhage. Nat Med 13:477-485

22. Heep A, Stoffel-Wagner B, Bartmann P, Benseler S, Schaller C, Groneck P, Obladen M, Felderhoff-Mueser U 2004 Vascular endothelial growth factor and transforming growth factor-betal are highly expressed in the cerebrospinal fluid of premature infants with posthemorrhagic hydrocephalus. Pediatr Res 56:768-774

23. Lashkari K, Hirose T, Yazdany J, McMeel JW, Kazlauskas A, Rahimi N 2000 Vascular endothelial growth factor and hepatocyte growth factor levels are differentially elevated in patients with advanced retinopathy of prematurity. Am J Pathol $156: 1337-1344$

24. Banyasz I, Bokodi G, Vasarhelyi B, Treszl A, Derzbach L, Szabo A, Tulassay T, Vannay A 2006 Genetic polymorphisms for vascular endothelial growth factor in perinatal complications. Eur Cytokine Netw 17:266-270

25. Frost BL, Jilling T, Caplan MS 2008 The importance of pro-inflammatory signaling in neonatal necrotizing enterocolitis. Semin Perinatol 32:100-106

26. Markel TA, Crisostomo PR, Wairiuko GM, Pitcher J, Tsai BM, Meldrum DR 2006 Cytokines in necrotizing enterocolitis. Shock 25:329-337 
27. Florio P, Perrone S, Luisi S, Vezzosi P, Longini M, Marzocchi B, Petraglia F, Buonocore G 2006 Increased plasma concentrations of activin a predict intraventricular hemorrhage in preterm newborns. Clin Chem 52:1516-1521

28. Lakhani N, Sparreboom A, Venitz J, Dahut WL, Figg WD 2006 Plasma protein binding of the investigational anticancer agent 2-methoxyestradiol. Anticancer Drugs 17:977-983

29. James J, Murry DJ, Treston AM, Storniolo AM, Sledge GW, Sidor C, Miller KD 2007 Phase I safety, pharmacokinetic and pharmacodynamic studies of 2-methoxyestradiol alone or in combination with docetaxel in patients with locally recurrent or metastatic breast cancer. Invest New Drugs 25:41-48

30. Moghrabi N, Head JR, Andersson S 1997 Cell type-specific expression of 17 beta-hydroxysteroid dehydrogenase type 2 in human placenta and fetal liver. J Clin Endocrinol Metab 82:3872-3878

31. Takeyama J, Sasano H, Suzuki T, Iinuma K, Nagura H, Andersson S 1998 17Beta-hydroxysteroid dehydrogenase types 1 and 2 in human placenta: an immunohistochemical study with correlation to placental development. J Clin Endocrinol Metab 83:3710-3715

32. Maentausta O, Sormunen R, Isomaa V, Lehto VP, Jouppila P, Vihko R 1991 Immunohistochemical localization of 17 beta-hydroxysteroid dehydrogenase in the human endometrium during the menstrual cycle. Lab Invest 65:582-587

33. Drolet R, Simard M, Plante J, Laberge P, Tremblay Y 2007 Human type 217 beta-hydroxysteroid dehydrogenase mRNA and protein distribution in placental villi at mid and term pregnancy. Reprod Biol Endocrinol 5:30

34. Troisi R, Potischman N, Roberts JM, Harger G, Markovic N, Cole B, Lykins D, Siiteri P, Hoover RN 2003 Correlation of serum hormone concentrations in maternal and umbilical cord samples. Cancer Epidemiol Biomarkers Prev 12:452-456

35. Wallner W, Sengenberger R, Strick R, Strissel PL, Meurer B, Beckmann MW, Schlembach D 2007 Angiogenic growth factors in maternal and fetal serum in pregnancies complicated by intrauterine growth restriction. Clin Sci (Lond) 112:51-57

36. Tsao PN, Wei SC, Su YN, Chou HC, Chen CY, Hsieh WS 2005 Excess soluble fms-like tyrosine kinase 1 and low platelet counts in premature neonates of preeclamptic mothers. Pediatrics 116:468-472

37. Staff AC, Braekke K, Harsem NK, Lyberg T, Holthe MR 2005 Circulating concentrations of sFlt1 (soluble FMS-like tyrosine kinase 1) in fetal and maternal serum during pre-eclampsia. Eur J Obstet Gynecol Reprod Biol 122:33-39

38. Malamitsi-Puchner A, Boutsikou T, Economou E, Makrakis E, Iliodromiti Z, Kouskouni E, Hassiakos D 2005 The role of the anti-angiogenic factor endostatin in intrauterine growth restriction. J Soc Gynecol Investig 12:195-197

39. Maynard SE, Min JY, Merchan J, Lim KH, Li J, Mondal S, Libermann TA, Morgan JP, Sellke FW, Stillman IE, Epstein FH, Sukhatme VP, Karumanchi SA 2003 Excess placental soluble FMS-like tyrosine kinase 1 (sFlt1) may contribute to endothelial dysfunction, hypertension, and proteinuria in preeclampsia. J Clin Invest 111:649658

40. LaVallee TM, Zhan XH, Johnson MS, Herbstritt CJ, Swartz G, Williams MS, Hembrough WA, Green SJ, Pribluda VS 2003 2-methoxyestradiol up-regulates death receptor 5 and induces apoptosis through activation of the extrinsic pathway. Cancer Res 63:468-475

41. Zacharia LC, Gogos JA, Karayiorgou M, Jackson EK, Gillespie DG, Barchiesi F, Dubey RK 2003 Methoxyestradiols mediate the antimitogenic effects of 17beta-estradiol: direct evidence from catechol-O-methyltransferase-knockout mice. Circulation 108:29742978

42. Dubey RK, Zacharia LC, Gillespie DG, Imthurn B, Jackson EK 2003 Catecholamines block the antimitogenic effect of estradiol on human glomerular mesangial cells. Hypertension 42:349-355 